\title{
Incident gout and weight change patterns: a retrospective cohort study of US adults
}

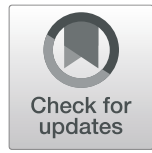

Lu Bai $^{1 \dagger}$, Jian-Bo Zhou ${ }^{2^{*}}$ (D), Tao Zhou ${ }^{3}$, Roger B. Newson ${ }^{4}$ and Marly Augusto Cardoso ${ }^{5}$

\begin{abstract}
Background: Although the relationship between obesity and incident gout has been clarified, the influence of weight changes during the transition from early adulthood to midlife and the different weight change patterns in specific age ranges on the incidence of gout in later life remain unknown. Therefore, we aimed to investigate the association between weight change patterns across adulthood and incident gout.

Methods: Using data from the National Health and Nutrition Examination Survey (NHANES), we categorized individuals into four weight change patterns: those who remained obese (stable obese), those who moved from a non-obese body mass index (BMI) to an obese BMI (gaining), those who moved from an obese BMI to a non-obese BMI (losing), and those who remained non-obese (stable non-obese). Incident gout reflected its occurrence over the 10-year follow-up from the recalled midlife weight measure to the time of this survey. Hazard ratios (HRs) and 95\% confidence intervals relating weight change patterns to incident gout over the 10-year follow-up period were calculated using Cox models adjusted for covariates. The hypothetical population attributable fraction (PAF) for the weight change patterns was calculated.
\end{abstract}

Results: Among our sample of adults aged 40-74 years at their midlife weight measure $(n=11,079), 320$ developed gout. The highest risk of incident gout was found for participants with the stable obese pattern (HR 1.84; 1.08-3.14) and not for participants who remained stable non-obese during adulthood. Moreover, gaining weight was a significant risk factor for incident gout (HR 1.65; 1.19-2.29). No significant associations were found between losing weight change patterns and the risk of gout during the study period. If participants who gained weight had become non-obese during the 10-year follow-up, an estimated 3.2\% (95\% Cl 0-6.3) of observed gout cases could have been averted. In addition, if the population had maintained a normal BMI, 32.9\% (95\% Cl 18.2-44.9) cases could have been prevented during the 10 years.

Conclusions: Gaining weight over adulthood was associated with an increased risk of gout. These findings have highlighted that maintaining non-obese weight and weight loss across adulthood is essential for the prevention and treatment of gout in adult life.

Keywords: Gout, Weight change, Cohort

\footnotetext{
* Correspondence: jbzhou@ccmu.edu.cn

${ }^{\dagger}$ Lu Bai and Jian-Bo Zhou contributed equally to this work.

${ }^{2}$ Department of Endocrinology, Beijing Tongren Hospital, Capital Medical University, Beijing, China

Full list of author information is available at the end of the article
}

(c) The Author(s). 2021 Open Access This article is licensed under a Creative Commons Attribution 4.0 International License, which permits use, sharing, adaptation, distribution and reproduction in any medium or format, as long as you give appropriate credit to the original author(s) and the source, provide a link to the Creative Commons licence, and indicate if changes were made. The images or other third party material in this article are included in the article's Creative Commons licence, unless indicated otherwise in a credit line to the material. If material is not included in the article's Creative Commons licence and your intended use is not permitted by statutory regulation or exceeds the permitted use, you will need to obtain permission directly from the copyright holder. To view a copy of this licence, visit http://creativecommons.org/licenses/by/4.0/ The Creative Commons Public Domain Dedication waiver (http://creativecommons.org/publicdomain/zero/1.0/) applies to the data made available in this article, unless otherwise stated in a credit line to the data. 


\section{Background}

Gout is a common form of inflammatory arthritis [1], with the overall prevalence of gout among US adults at $3.9 \%$ [2]. Characterized by monosodium urate (MSU) crystal deposition resulting from chronic elevation of serum uric acid (SUA) levels [3, 4], gout can lead to severe arthropathies, physical impairment, and a decreased quality of life [5]. The general management principle is to reduce SUA levels, allowing MSU crystals to dissolve, leading to the elimination of acute attacks, and possibly curing the disease [6-8]. A large epidemiological study has indicated that the worldwide prevalence of gout is on an upward trend, with increasing obesity being a significant risk factor for gout development [9]. Gout is also affected by numerous factors, including intake of sugar-sweetened beverages (SSB), alcohol consumption, renal disease, and the use of diuretics and antihypertensive drugs [10-12]. A recently published meta-analysis indicated that SSB consumption was significantly associated with an increased risk of gout in the adult population [13]. Obesity is also a major global health challenge [14]. The association between obesity and gout may be attributed to insulin resistance, which in turn reduces renal urate excretion, resulting in hyperuricemia [15]. The American College of Rheumatology guidelines recommend weight loss as part of gout management for patients with obesity [16].

Although some prospective studies have clarified the relationship between obesity and the incidence of gout [17-21], the influence of weight changes during the transition from early adulthood to midlife and the different weight change patterns in specific age ranges on the incidence of gout in later life remain unknown. Hence, assessment of the population-level effect of weight change across the life course on incident gout risk is needed.

We test a hypothesis that individuals who were losing weight had a higher risk of gout than individuals who maintained a non-obese BMI over time ("residual risk" hypothesis), which means that individuals who have been obese are at higher risk of developing gout than those who have never been obese. Therefore, we aimed to investigate the association between weight change patterns across adulthood and incident gout.

\section{Methods}

\section{Data sources}

This was a retrospective longitudinal study using national data from the National Health and Nutrition Examination Survey (NHANES) (2007-2014), which is a nationally representative sample of US adults. The survey contains information on graphic characteristic, weight history, and health behaviors/conditions [22]. We used the data of adults aged 40-74 years who participated in NHANES during this period. Selfreported weight change was assessed based on the participants' memory recall of weight at age 25 and 10 years prior to participation in NHANES. Gout status was determined by a self-report of a prior diagnosis, and age at diagnosis was used to establish the time of gout onset. Therefore, we investigated the association between weight change and the risk of incident gout over the 10 years from the midlife measure to the time of the survey. The study design depicted in Fig. 1 was modified from a similar analysis of incident diabetes [23]. Institutional Review Board approval was not required for this study because the investigation was based on secondary analyses of publicly available, deidentified data.

\section{Weight change measures}

Participants were requested to recall their weight at age 25 and 10 years prior to participation in NHANES. In this study, BMI at age 25 was calculated using the reported height at age 25, which we considered as young adulthood. Likewise, we regarded the recalled weight 10 years prior to the survey as a measure of midlife weight. Owing to the possibility of declining height with age, the reported height at age 25 was used. The height measured in the survey was used to calculate the BMI at midlife. $\mathrm{BMI}$ at age $25\left(\mathrm{BMI}_{25}\right)$ and 10 years prior to the survey $\left(\mathrm{BMI}_{10 \text { prior })}\right.$ was calculated as weight $(\mathrm{kg})$ divided by the square of height $\left(\mathrm{m}^{2}\right)$. BMI change patterns, according to the BMI change trajectory were categorized into four groups from $\mathrm{BMI}_{25}$ to $\mathrm{BMI}_{10}$ prior. The groups were as follows [1]: stable non-obese, $\mathrm{BMI}_{25}<30 \mathrm{~kg} / \mathrm{m}^{2}$ and $\mathrm{BMI}_{10}$ prior $<30 \mathrm{~kg} / \mathrm{m}^{2}$; losing, $\mathrm{BMI}_{25} \geq 30 \mathrm{~kg} / \mathrm{m}^{2}$ and $\mathrm{BMI}_{10}$ prior $<30 \mathrm{~kg} / \mathrm{m}^{2}$; gaining, $\mathrm{BMI}_{25}<30 \mathrm{~kg} / \mathrm{m}^{2}$ and $\mathrm{BMI}_{10}$ prior $\geq 30 \mathrm{~kg} / \mathrm{m}^{2}$; and stable obese, $\mathrm{BMI}_{25} \geq 30 \mathrm{~kg} /$ $\mathrm{m}^{2}$ and $\mathrm{BMI}_{10}$ prior $\geq 30 \mathrm{~kg} / \mathrm{m}^{2}$.

\section{Assessment of incident gout}

Participants were considered to have gout if they reported in the survey that they had been diagnosed by a health care provider as having gout (gout incidence during follow-up was included based on the information on gout diagnosis and the use of gout medications).

\section{Statistical analysis}

Tests of statistical significance were two-tailed, with a significance level of 0.05. STATA15.0 (StataCorp LLC, College Station, TX, USA) was used for all analyses. All analyses were performed using SUDAAN (SUDAAN Language Manual, Release 9.0, 2004; Research Triangle Institute, NC, USA), which considered the complex sampling design used in NHANES, thus yielding unbiased standard error estimates [24]. The percentages of missing values of covariates were less than $5 \%$, except for income (6.8\%) [24]. We compared the baseline 
Recalled weight at age 25

to calculate $\mathrm{BMI}_{25}$

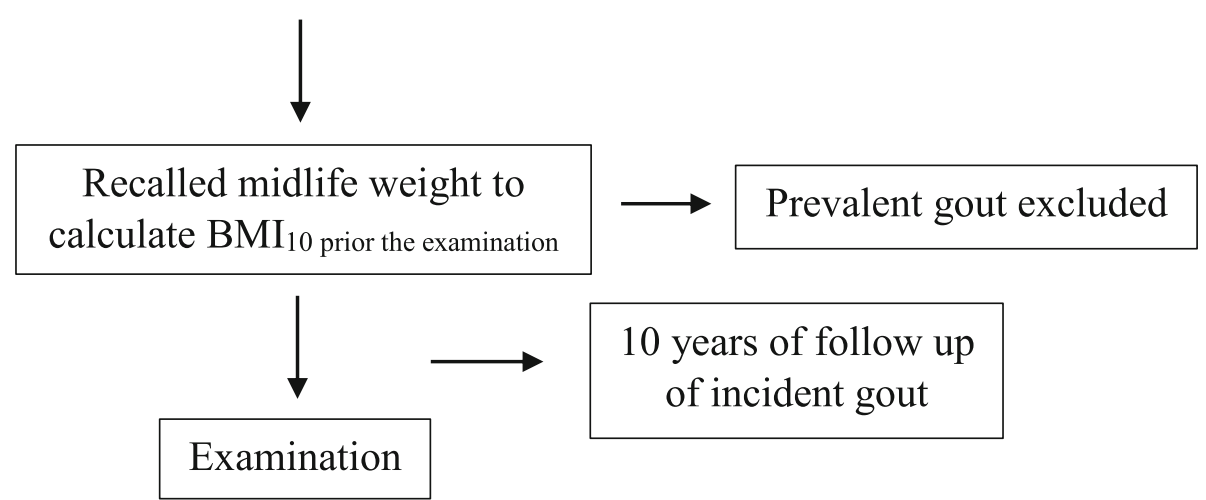

Fig. 1 Study design for analysis of incident gout $(n=11,079)$. Creation of a cross-sectional, retrospective cohort of US adults. We studied individuals who participated in the NHANES (2007-2014) cross-sectional survey at ages 40-74 years. It was based on the participants' memory recalled weight history at age 25 (young adulthood) and 10 years before the survey (age 30-64 years, midlife), which was used to create a measure of weight change between young adulthood and midlife. We then investigated the association between this weight change and the successive risk of developing gout. "Follow-up" for incident gout began 10 years before the survey. Individuals who reported receiving a first diagnosis of gout between 10 years before the survey and time of the survey were considered to have incident gout

characteristics by weight change patterns using the $\chi^{2}$ test for categorical variables and an analysis of variance adjusted for sampling weights for continuous variables.

Our hypothesis that individuals who were obese or gained weight had a higher risk of gout than individuals who maintained a non-obese BMI over time ("residual risk" hypothesis) was tested using Cox models to predict the rate of incident gout across the four BMI change groups over the 10 years. Stable non-obese weight change patterns were used as the reference category against which all the other weight change patterns were compared. The models included adjustments for ethnicity, sex, age, current smoking (yes/no), annual household income, diabetes, hypertension, and consuming alcohol.

\section{Hypothetical scenarios}

Estimates of the percentage of gout cases that could be averted under three hypothetical scenarios were calculated using the following equation for the population attributable fraction (PAF):

$$
P A F=\sum_{i=0}^{k} p d_{i}\left(\frac{H R_{i}-1}{H R_{i}}\right)
$$

where $p d_{i}$ was the proportion of total incident cases in the sample observed in the $i$ th weight change category and $H R_{i}$ was the hazard ratio associated with that category [25]. We estimated the fraction of cases that would be eliminated if a weight change category was redistributed to another category. To allow for a valid calculation of PAF, logistic regression models with covariates were included in the model. For these analyses, we used a single binary categorical variable and compared participants in the weight change category with the rest of the population to calculate the PAF in the total population for the relevant individuals [26].

In the first scenario, we estimated what would have happened if those who were gaining weight had a nonobese BMI at age 25 and during midlife. In the second scenario, we calculated the proportion of averted cases if those who had a stable obese BMI during the period had a non-obese weight. In the third scenario, we examined the percentage of the entire population if participants had a normal BMI at age 25 and during midlife.

\section{Results}

\section{Clinical features of the participants}

The clinical characteristics of the participants according to the weight change category are shown in Table 1 . Overall, 11,079 participants were included in the study, and 320 cases of incident gout were identified during the 10-year follow-up. More than half of the sample (78.2\%) maintained their BMI category. In specific, 7945 (71.7\%) participants were in the stable non-obese group; losing group was rare, with 115 (1.0\%); 2307 (20.8\%) were gaining group; and 712 (6.5\%) were stable obese group.

Different weight change patterns showed a different prevalence of comorbidities, such as diabetes mellitus (6.8\%, stable non-obese group; $15.8 \%$, losing group; $24.6 \%$, gaining group; and $25.9 \%$, the stable obese group) and hypertension (33.2\%, stable non-obese group; $41.8 \%$, 
Table 1 Characteristics at survey of weight change patterns from age 25 to 10 years prior to the survey in adults ages $40-74$ years* $(N=11,079)$

\begin{tabular}{|c|c|c|c|c|}
\hline & Stable non-obese & Losing body weight & Gaining body weight & Stable obese \\
\hline No of participates, $n$ (\%) & $7945(71.7)$ & $115(1.0)$ & $2307(20.8)$ & $712(6.5)$ \\
\hline Age (years), (95\% Cl) & $54.1(53.7-54.4)$ & $52.0(50.6-53.5)$ & $56.8(56.2-57.4)$ & $51.3(50.4-52.1)$ \\
\hline Female, $n(\%)$ & $4082(53.0)$ & $49(45.5)$ & $1198(49.9)$ & $368(46.6)$ \\
\hline Black, $n(\%)$ & 1699 (9.9) & $27(16.2)$ & $578(11.6)$ & $239(17.3)$ \\
\hline Current smoke, $n(\%)$ & $1799(21.1)$ & $39(34.9)$ & $386(16.4)$ & $150(18.3)$ \\
\hline Alcohol consumption (drinks/day), (95\% Cl) & $1.6(1.6-1.7)$ & $2.1(1.5-2.8)$ & $1.4(1.3-1.5)$ & $1.7(1.4-2.0)$ \\
\hline Diabetes, $n(\%)$ & $793(6.8)$ & $22(15.8)$ & $684(24.6)$ & $217(25.9)$ \\
\hline Hypertension, n (\%) & $2978(33.2)$ & $48(41.8)$ & $1392(57.1)$ & $419(56.5)$ \\
\hline Annual household income $\geq 65,000 \$, n(\%)$ & $2644(47.8)$ & $29(32.1)$ & $671(41.4)$ & $187(38.4)$ \\
\hline \multicolumn{5}{|l|}{ BMl, mean $(95 \% \mathrm{Cl}), \mathrm{kg} / \mathrm{m}^{2}$} \\
\hline At 25 years of age $e^{a}$ & $22.1(22.0-22.2)$ & $34.5(33.1-35.9)$ & $24.9(24.7-25.1)$ & $34.7(34.1-35.2)$ \\
\hline At 10 years prior ${ }^{b}$ & $24.6(24.5-24.7)$ & $26.7(26.0-27.4)$ & $34.2(34.0-34.5)$ & $39.0(38.2-39.9)$ \\
\hline At examination ${ }^{c}$ & $26.9(26.7-27.0)$ & $30.5(28.9-32.1)$ & $34.8(34.5-35.1)$ & $39.3(38.5-40.2)$ \\
\hline Serum uric acid (mg/dL) & $5.30(5.25-5.35)$ & $5.65(5.23-6.08)$ & $5.82(5.73-5.90)$ & $5.93(5.77-6.10)$ \\
\hline
\end{tabular}

*NHANES (2007-2014); sample weighted estimates

aSelf-reported BMI at 25 years of age

${ }^{\mathrm{b}}$ Self-reported BMI 10 years before examination

'Self-reported BMI at examination

losing group; 57.1\%, gaining group; and 56.5\%, stable obese group).

\section{Association of weight change patterns and incident gout} Compared with that of stable non-obese participants, stable obese participants had a higher risk (1.84; 95\% CI 1.08-3.14) of developing gout. Those who gained weight from young adulthood through midlife had 1.65 times (95\% CI 1.19-2.29) the risk of developing gout during the 10-year follow-up (Table 2). No significant difference (HR 0.48; 95\% CI 0.09-2.61) was observed in the risk of gout onset between those reporting a shift from an obese BMI to a non-obese BMI over the study period.

\section{Cumulative incident gout defined by the onset in the recent 10 years according to the obesity track}

Figure 2 illustrates the cumulative incidence curves by time for each weight change group. The cumulative incidence of onset gout was $1.96 \%$ (95\% CI, 1.58-2.43) for

Table 2 Residual risk: HRs for weight change and incident gout, NHANES (2007-2014) $(n=11,079)$

\begin{tabular}{llll}
\hline Obesity track & $\mathbf{H R}^{\dagger}$ & $\mathbf{9 5 \%}$ confidence interval & $\boldsymbol{P}$ value \\
\hline Stable obese & 1.84 & $(1.08-3.14)$ & 0.02 \\
Gaining weight & 1.65 & $(1.19-2.29)$ & 0.003 \\
Losing weight & 0.48 & $(0.09-2.61)$ & 0.39 \\
Stable non-obese & Reference & 1.0 & \\
\hline
\end{tabular}

NHANES National Health and Nutrition Examination Survey (2007-2014) ${ }^{\dagger}$ Adjusted for ethnicity, sex, age, current smoke (yes/no), annual household income, diabetes, hypertension, and alcohol consumption sustained non-obese, $0.87 \%$ (95\% CI, 0.15-4.74) for loss, 4.19\% (95\% CI, 3.31-5.28) for gain, and 4.12\% (95\% CI, 2.53-6.63) for stable obesity.

\section{Hypothetical scenarios}

The three hypothetical scenarios that were defined earlier were used to calculate the PAFs (Table 3). In the first scenario, if those who were gaining weight but had a non-obese BMI, 11.5\% (95\% CI 4.6-17.9) of observed gout cases could have been averted. In the second scenario, if those who maintained an obese BMI during the period had a non-obese weight, $3.2 \%$ (95\% CI 0-6.3) of the observed cases could have been averted. In the third scenario, maintaining a normal BMI between young adulthood and midlife of the total population could have prevented 32.9\% (95\% CI 18.2-44.9) of gout cases.

\section{Discussion}

Our objective was to evaluate the relationship between obesity and weight change and the incidence of gout in a large retrospective study of nationally representative US adults. We found that participants with a stable obese BMI gaining weight to shift from a non-obese to an obese group were consistently associated with the risk of gout. These results also emphasized the importance of maintaining non-obese weight across adulthood, especially weight loss for obese individuals, for reducing gout risk in later life. 


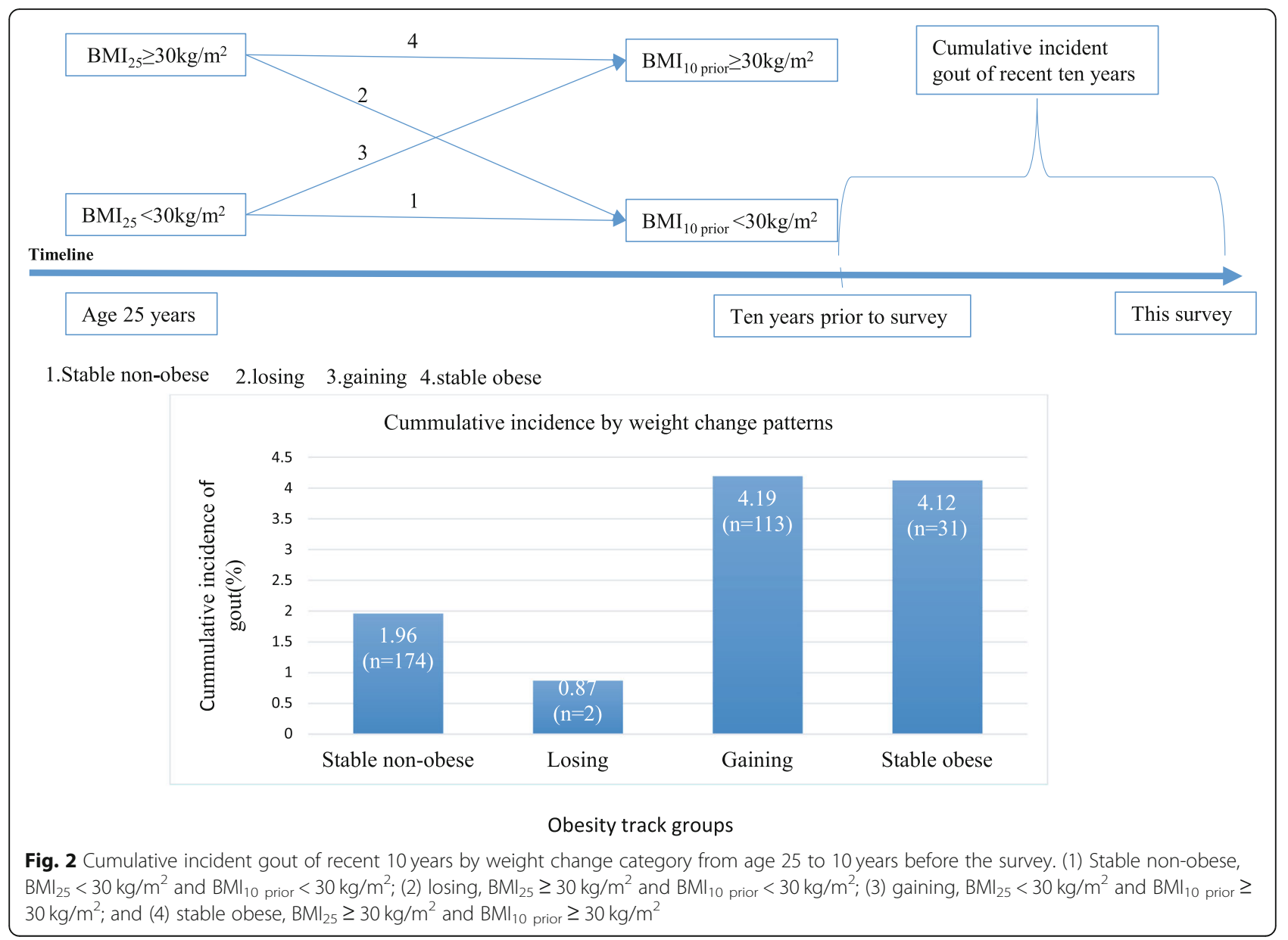

\section{Comparisons between previous studies and our results}

The risk of incident gout owing to the increased BMI was substantial. In our cohort, participants with an obese BMI and who had a stable obese BMI had a high possibility of developing gout. Since the prevalence of obesity continues to rise, having reached $37.7 \%$ according to NHANES [27], the absolute excess risk of gout due to excess weight is also expected to increase. These results expanded on the findings of previous studies on weight change and gout. A study conducted in China had found that those who had a weight gain of $5 \mathrm{~kg}, 20 \mathrm{~kg}$, or higher from early to midlife were associated with a higher risk of gout, regardless of sex [28]. Furthermore, a systematic review and meta-analysis had found that in obese individuals, gout was 2.24 times more likely to occur than in those with normal weight [29]. A population-based cohort study had also indicated that obese individuals have an adjusted 2.4-fold higher risk of developing gout than non-obese individuals during a 9year follow-up [20]. The Health Professionals Follow-up Study (HPFS) [30] prospectively evaluated the relations between BMI, weight change, and incident gout. It had

Table 3 Population attributable fractions (PAF) for population counterfactuals of incident gout among weight change patterns across adulthood

\begin{tabular}{lll}
\hline Scenario $^{\dagger}$ & PAF (\%), 95\% Cl total population & PAF (\%), 95\% Cl subpopulation $^{\#}$ \\
\hline 1. From gaining to stable non-obese & $11.5(4.6-17.9)$ & $36.4(18.6-50.3)$ \\
2. From stable obese to stable non-obese & $3.2(0-6.3)$ & $37.6(6.0-58.7)$ \\
3. Total population to stable normal & $32.9(18.2-44.9)$ & $42.8(25.8-55.9)$
\end{tabular}

Source: NHANES (2007-2014)

${ }^{\dagger}$ Adjusted for ethnicity, sex, age, current smoke (yes/no), annual household income, diabetes, hypertension, and alcohol consumption

From a younger age to an older age: scenario 1, if those who gained weight, instead remained non-obese; scenario 2, if those who maintained an obese BMI, instead lost to a non-obese BMl; scenario 3, if the total population had a normal BMI from young adulthood that was maintained through midlife

"Scenario 1: subpopulation represents the gaining group; scenario 2: subpopulation represents the stable obese group; scenario 3: subpopulation represents the population whose $\mathrm{BMI} \geq 25 \mathrm{~kg} / \mathrm{m}^{2}$ 
found that weight gain since young adulthood was strongly associated with the risk of gout, even after adjusting for age, hypertension, alcohol consumption, and diet. These findings supported the results from our study that the HRs of gout were 1.65 for gaining individuals and 1.84 for stable obese individuals during the 10year period. Studies have also found that the cumulative incidence of gout at age 70 was $11.8 \%$ with BMI $\geq 35 \mathrm{~kg} /$ $\mathrm{m}^{2}$, but it was only $1.9 \%$ in those with BMI $<25 \mathrm{~kg} / \mathrm{m}$ $[29,31]$. Similar results were observed in our study stratified by weight change patterns from age 25 to 10 years prior to the survey, with the following cumulative incidence curves by time for each weight change group: $1.96 \%(1.58-2.43)$ for stable non-obese, $0.87 \%$ (0.154.74) for losing, $4.19 \%$ (3.31-5.28) for gaining, and $4.12 \%$ (2.53-6.63) for stable obesity. The potential impact of weight gain on the incidence of gout was substantial.

Nonetheless, we found that weight loss was associated with a reduced risk of gout. Likewise, gout patients losing weight through bariatric surgery or diet experienced reduced flare frequency [32]. A meta-analysis of prospective studies had suggested that obesity was associated with a dose-dependent increase in the relative risks (RRs) of incident gout and that gout incidence could have been lessened by interventions aimed at obesity [33]. The hypothetical scenarios targeted to explore the potential effect of weight gain and weight loss interventions.

In the hypothetical scenario preventing weight gain in the population after age 25 and maintaining a non-obese BMI, an $11.5 \%$ (95\% CI 4.6-17.9) reduction in gout cases in the population could have occurred. If all those who were obese at age 25 lost to a non-obese BMI by midlife, $3.2 \%$ (95\% CI 0-6.3) of observed incident gout could have been averted. Likewise, we found that 32.9\% (95\% CI 18.2-44.9) of gout cases during this period could have been averted if all individuals in the population maintained a normal weight from early adulthood to midlife. Our hypothetical scenarios were consistent with previous studies that examined the effect of weight loss on gout.

Studies on the effects of weight loss interventions from either bariatric surgery or lifestyle modification (moderate calorie/carbohydrate restriction, increased proportional intake of protein and unsaturated fat) also reported a reduced incidence of gout [32, 34, 35]. A systematic review [36] shows that a weight loss of $>3.5 \mathrm{~kg}$ showed beneficial effects on gout attacks at mediumterm/long-term follow-up. However, in our study, the losing group had a wide $95 \%$ CI because weight loss from an obese BMI to a non-obese BMI was rare, accounting for only $1.0 \%$ of the total population.

\section{Potential mechanisms}

In some studies [37, 38], weight gain has been associated with increasing SUA levels. Conversely, weight loss reduced the level of SUA $[39,40]$. A study showed that a higher BMI increased the risk of gout by increasing the SUA level [30], with high SUA levels resulting in the formation of MSU crystals [41], which then contributed to an inflammatory response with tissue damage [42, 43]. Obesity possibly increased the production of MSU crystals and reduced renal excretion of urate [44, 45], causing hyperuricemia. Although most people with hyperuricemia do not have gout, increased SUA levels can still raise the risk of developing gout [46]. Several studies have demonstrated a strong association among gout, SUA levels, obesity, and metabolic syndrome, including hypertension and dyslipidemia [22, 47, 48]. The study by Lyndgoh et al. [49] revealed that raised SUA levels were an outcome but not a cause of obesity, which had been assumed to lead to high SUA levels causing impaired nitric oxide production, endothelial dysfunction, enhanced oxidative stress, and maladaptive immune and inflammatory responses [50].

In 2020, the ACR Guideline for the Management of Gout [51] was conditionally recommended in areas such as diet (alcohol intake, vitamin $\mathrm{C}$ supplement, and highfructose intake), lifestyle, or concomitant medications, which might have affected the SUA levels in gout patients. The NRHS [52] cohort showed a 51\% reduction in the risk of gout with a high intake of fruit, whereas the HPFS [53] cohort showed a $63 \%$ increased risk. The results of the two studies were conflicting, and we assumed that while the HPFS cohort [53] included fruit with high-fructose content, the NRHS [52] cohort included fruit that may have represented a healthier dietary intake. In short-term feeding trials and experimental studies, high-fructose intake resulted in hyperuricemia and incident gout and increased insulin resistance [53, 54]. In NHANES, artificially sweetened carbonated beverage consumption was associated with higher SUA levels [55]. In addition, a crosssectional study has suggested that cereal and yogurt consumption may have been associated with a lower SUA level [56]. Urate-lowering therapy was highly recommended in the 2020 ACR Guideline for the Management of Gout, which had high quality of evidence supporting its use as an efficient treatment in reducing flare frequency and SUA levels [57-59].

\section{Strengths and limitation}

The strengths of our study are as follows: first, the use of a retrospective cohort design allowed us to take advantage of a large, nationally representative cohort of US adults to estimate associations between weight change and incident gout from early adulthood to midlife. Therefore, our estimates are broadly generalizable to the US population. Second, we tested a hypothesis concerning the residual risk associated with previously having a higher weight. 
This study also had several limitations. First, weight at early adulthood was recalled at a later age, and some misclassifications of weight change were inevitable. However, evidence has demonstrated that historic weight measures can have high agreement with the measured weight $[60,61]$. Second, although spurious estimates of BMI may have been made when relying on self-reported height at age 25 in adults older than age 50 to calculate BMI at age 25 [62], evidence has suggested a relatively high level of accordance between height recall and historically measured height among older adults [63, 64]. Third, the definition of gout in epidemiological studies varies and includes, either in isolation or combination, physician-diagnosed gout based on history and examination, prescription practices, and analysis of healthcare datasets or coding systems. We believe that the self-reporting of medically diagnosed gout is the real definition for epidemiological purposes, which is supported by a 2011 US study that explicitly addresses the question of reliability and sensitivity of self-reported physician-diagnosed gout [65]. Using a large cohort consisting of more than 32,000 participants, this group found that self-reported physician-diagnosed gout was consistent over multiple questionnaires and the duration of time. Self-reported of physician-diagnosed gout had a sensitivity of $84 \%$ while compared with that of the gold standard, which was defined as a hospital discharge diagnosis of gout or use of gout-specific medications (colchicine, probenecid, allopurinol).

\section{Conclusions}

The NHANES survey data were analyzed using a novel application to explore the relationship between weight change patterns and incident gout through early adulthood to midlife. Regarding the residual risk hypothesis, those who were stable obese had a higher risk of incident gout than those who remained non-obese throughout the life span. Our hypothetical scenarios indicated beneficial effects of positive weight intervention change from either stable obese or gaining weight to sustained normal or from stable obese to weight loss. Taken together, the findings support that maintaining normal weight over the whole of adulthood is beneficial reduces the risk of gout among obese individuals. The significance of developing policies and programs that reduce the prevalence of obesity is underscored by the results of our study. Identifying populations at risk of developing gout may provide opportunities for primary prevention. Clinical trials on long-term health consequences of weight intervention are warranted.

\section{Abbreviations}

BMI: Body mass index; SUA: Serum uric acid; PAF: Population attributable fraction; HR: Hazard ratios; NHANES: National Health and Nutritional Examination Survey
Acknowledgements

The authors thank the staff in this study for their indispensable contribution.

\section{Authors' contributions}

JBZ and LB contributed to studying the concept and design, acquisition of data, analysis and interpretation of data, and critical revision of the manuscript for important intellectual content. LB drafted the manuscript, TZ, RBN, and MAC revised the manuscript, and all authors read and approved the final manuscript

\section{Funding}

This work was supported by the National Natural Science Foundation of China (No. 82070851, 81870556, 81670738), Beijing Municipal Administration of Hospital's Youth Program (QML20170204), Excellent Talents in Dongcheng District of Beijing.

\section{Availability of data and materials}

Data from the National Health and Nutritional Examination Survey are available online through the CDC.

\section{Declarations}

Ethics approval and consent to participate

Not applicable.

\section{Consent for publication}

Not applicable.

\section{Competing interests}

The authors declare no competing interests.

\section{Author details}

${ }^{1}$ Hospice \& Palliative Care Unit, Haidian Section of Peking University Third Hospital, Beijing, China. ${ }^{2}$ Department of Endocrinology, Beijing Tongren Hospital, Capital Medical University, Beijing, China. ${ }^{3}$ School of Public Health (Shenzhen), Sun Yat-sen University, Guangzhou 510006, Guangdong, China. ${ }^{4}$ Department of Primary Care and Public Health, Imperial College London, London, UK. ${ }^{5}$ Department of Nutrition, School of Public Health, University of Sao Paulo, Sao Paulo, Brazil.

Received: 28 July 2020 Accepted: 22 February 2021

Published online: 02 March 2021

References

1. Smith EU, Díaz-Torné C, Perez-Ruiz F, March LM. Epidemiology of gout: an update. Best Pract Res Clin Rheumatol. 2010;24:811-27.

2. Singh $G$, Lingala $B$, Mithal $A$. Gout and hyperuricaemia in the USA: prevalence and trends. Rheumatology. 2019:58:2177-80.

3. Dalbeth N, Fransen J, Jansen TL, Neogi T, Schumacher HR, Taylor WJ. New classification criteria for gout: a framework for progress. Rheumatology. 2013;52:1748-53.

4. Neogi T, Jansen TL, Dalbeth N, Fransen J, Schumacher HR, Berendsen D, et al. Gout classification criteria: an American College of Rheumatology/ European League against Rheumatism collaborative initiative. Ann Rheum Dis. 2015;74:1789-98.

5. Scire CA, Manara M, Cimmino MA, Govoni M, Salaffi F, Punzi L, et al. Gout impacts on function and health-related quality of life beyond associated risk factors and medical conditions: results from the KING observational study of the Italian Society for Rheumatology (SIR) Arthritis. Res Ther. 2013;15:R101.

6. Bernal JA, Quilis N, Andrés M, Sivera F, Pascual E. Gout: optimizing treatment to achieve a disease cure. Ther Adv Chronic Dis. 2016;7:135-44.

7. Grassi D, Pontremoli R, Bocale R, Ferri C, Desideri G. Therapeutic approaches to chronic hyperuricemia and gout. High Blood Press Cardiovasc Prev. 2014; 21:243-50.

8. Kiltz U, Smolen J, Bardin T, Cohen SA, Dalbeth N, Doherty M, et al. Treat-totarget (T2T) recommendations for gout. Ann Rheum Dis. 2016;76:1-7.

9. Roddy E, Choi HK. Epidemiology of gout. Rheum Dis Clin N Am. 2014;40: $155-75$

10. Delbeth N, Merriman TR, Stamp LK. Gout. Lancet. 2016;388:2039-52.

11. Kuo CF, Grainge MJ, Zhang W, Doherty M. Global epidemiology of gout: prevalence,incidence and risk factors. Nat Rev Rheumatol. 2015;11:649-62. 
12. Rai SK, Fung TT, Lu N, Keller SF, Curhan GC, Choi HK. The dietary approaches to stop hypertension (DASH) diet, western diet, and risk of gout in men: prospective cohort study. BMJ. 2017;357:j1794.

13. Ebrahimpour-Koujan S, Saneei P, Larijani B, Esmaillzadeh A. Consumption of sugar sweetened beverages and dietary fructose in relation to risk of gout and hyperuricemia: a systematic review and meta-analysis. Crit Rev Food Sci Nutr. 2020;60:1-10

14. World Health Organization. Obesity. http://www.who.int/gho/ncd/risk_fa ctors/obesity_text/en/. Accessed 14 Aug 2016.

15. Ter Maaten JC, Voorburg A, Heine RJ, Ter Wee PM, Donker AJ, Gans RO. Renal handling of urate and sodium during acute physiological hyperinsulinaemia in healthy subjects. Clin Sci (Lond). 1997;92:51-8.

16. Khanna D, Fitzgerald JD, Khanna PP, Bae S, Singh MK, Neogi T, et al. American College of Rheumatology guidelines for management of gout. Part 1: systematic nonpharmacologic and pharmacologic therapeutic approaches to hyperuricemia. Arthritis Care Res. 2012;64:1431-46.

17. Bhole V, de Vera M, Rahman MM, Krishnan E, Choi H. Epidemiology of gout in women: fifty-two-year follow-up of a prospective cohort. Arthritis Rheum. 2010;62:1069-76.

18. Cea Soriano L, Rothenbacher D, Choi HK, Garcia Rodriguez LA. Contemporary epidemiology of gout in the UK general population. Arthritis Res Ther. 2011;13:R39.

19. Maynard JW, McAdams DeMarco MA, Baer AN, Kottgen A, Folsom AR, Coresh J, et al. Incident gout in women and association with obesity in the atherosclerosis risk in communities (ARIC) study. Am J Med. 2012;125:717. e9-e17.

20. McAdams-DeMarco MA, Maynard JW, Baer AN, Coresh J. Hypertension and the risk of incident gout in a population-based study: the atherosclerosis risk in communities cohort. J Clin Hypertens (Greenwich). 2012;14:675-9.

21. Chen JH, Pan WH, Hsu CC, Yeh WT, Chuang SY, Chen PY, et al. Impact of obesity and hypertriglyceridemia on gout development with or without hyperuricemia: a prospective study. Arthritis Care Res (Hoboken). 2013;65: $133-40$

22. Centers for Disease Control and Prevention (CDC). About the National Health and Nutrition Examination Survey. 2017 https://www.cdc.gov/nchs/ nhanes/about_nhanes.htm.

23. Strokes A, Collins JM, Grant BF, Scamuffa RF, Hsiao CW, Johnston SS, et al. Obesity progression between young adulthood and midlife and incident diabetes: a retrospective cohort study of U.S. adults. Diabetes Care. 2018; 41(5):1025-31.

24. Yuan Y. Multiple imputation using SAS software. J StatSoftw. 2011;45:1-25.

25. Rockhill B, Newman B, Weinberg C. Use and misuse of population attributable fractions. Am J Public Health. 1998:88:15-9.

26. Wacholder S, Benichou J, Heineman EF, Hartge P, Hoover RN. Attributable risk: advantages of a broad definition of exposure. Am J Epidemiol. 1994; 140:303-9.

27. Flegal KM, Kruszon-Moran D, Carroll MD, Fryar CD, Ogden CL. Trends in obesity among adults in the United States, 2005 to 2014. JAMA. 2016; 315(21):2284-91.

28. Jia G, Shu X-O, Liu Y, Li H, Cai H, Gao J, et al. Association of adult weight gain with major health outcomes among middle-aged Chinese persons with low body weight in early adulthood. JAMA Network Open. 2019;2: e1917371.

29. Peter LE, James AP, John B, Christian DM, Charles AH, Edward R. Obesity, hypertension and diuretic use as risk factors for incident gout: a systematic review and meta-analysis of cohort studies. Arthritis Res Ther. 2018;20:1301-11.

30. Choi HK, Atkinson K, Karlson EW, Curhan G. Obesity, weight change, hypertension, diuretic use, and risk of gout in men: the health professionals follow-up study. Arch Intern Med. 2005:165:742-8.

31. Puig JG, Martinez MA. Hyperuricemia, gout and the metabolic syndrome. Curr Opin Rheumatol. 2008:20:187-91.

32. Dessein $\mathrm{PH}$, Shipton $\mathrm{EA}$, Stanwix $\mathrm{AE}$, Joffe BI, Ramokgadi J. Beneficial effects of weight loss associated with moderate calorie/carbohydrate restriction and increased proportional intake of protein and unsaturated fat on serum urate and lipoprotein levels in gout: a pilot study. Ann Rheum Dis. 2000;59: 539-43.

33. Dagfifinn A, Teresa N, Lars JV. Body mass index and the risk of gout: a systematic review and dose-response meta-analysis of prospective studies. Eur J Nutr. 2014;53:1591-601.

34. Dalbeth N, Chen P, White M, Gamble GD, Barratt-Boyes C, Gow PJ, et al. Impact of bariatric surgery on serum urate targets in people with morbid obesity and diabetes: a prospective longitudinal study. Ann Rheum Dis. 2014:73:797-802.

35. Maglio C, Peltonen $M$, Neovius $M$, Jacobson $P$, Jacobsson $L$, Rudin A, Carlsson LM. Effects of bariatric surgery on gout incidence in the Swedish Obese Subjects study: a non-randomised, prospective, controlled intervention trial. Ann Rheum Dis. 2016;76:688-93.

36. Nielsen SM, Bartels EM, Henriksen M, Wæhrens EE, Gudbergsen H, Bliddal H. Weight loss for overweight and obese individuals with gout: a systematic review of longitudinal studies. Ann Rheum Dis. 2017;76:1870-82.

37. Glynn RJ, Campion EW, Silbert JE. Trends in serum uric acid levels 1961 1980. Arthritis Rheum. 1983;26:87-93.

38. Villegas $\mathrm{R}$, Xiang YB, Cai QY, Fazio S, Linton MR, Li HL, et al. Prevalence and determinants of hyperuricemia in middle-aged, urban Chinese men. Metab Syndr Relat Disord. 2010;8:263-70.

39. Yamashita S, Matsuzawa Y, Tokunaga K, Fujioka S, Tarui S. Studies on the impaired metabolism of uric acid in obese subjects: marked reduction of renal urate excretion and its improvement by a low-calorie diet. Int J Obes. 1986;10:255-64.

40. Zhu Y, Zhang Y, Choi HK. The serum urate-lowering impact of weight loss among men with a high cardiovascular risk profile: The Multiple Risk Factor Intervention Trial. Rheumatology (Oxford). 2010:49:2391-9.

41. McGill NW. The epidemiology and treatment of gout. Open Access Rheumatol Res Rev. 2011:3:73-82.

42. Cleophas MC, Crisan TO, Joosten LA. Factors modulating the inflammatory response in acute gouty arthritis. Curr Opin Rheumatol. 2017;29:163-70.

43. Joosten LA, Netea MG, Mylona E, Koenders MI, Malireddi RK, Oosting M, et al. Engagement of fatty acids with toll-like receptor 2 drives interleukin1 beta production via the ASC/caspase 1 pathway in monosodium urate monohydrate crystal-induced gouty arthritis. Arthritis Rheum. 2010;62:323748.

44. Matsuura F, Yamashita S, Nakamura T, Nishida M, Nozaki S, Funahashi T, et al. Effect of visceral fat accumulation on uric acid metabolism in male obese subjects: visceral fat obesity is linked more closely to overproduction of uric acid than subcutaneous fat obesity. Metabolism. 1998;47:929-33.

45. Gao B, Zhou J, Ge J, Zhang YP, Chen F, Lau WB, et al. Association of maximum weight with hyperuricemia risk: a retrospective study of 21,414 Chinese people. PLoS One. 2012;7:e51186.

46. Shiozawa A, Szabo SM, Bolzani A, Cheung A, Choi HK. Serum uric acid and the risk of incident and recurrent gout: a systematic review. J Rheumatol. 2017:44:388-96

47. Heinig M, Johnson RJ. Role of uric acid in hypertension, renal disease, and metabolic syndrome. Cleve Clin J Med. 2006;73:1059-64.

48. Soltani Z, Rasheed K, Kapusta DR, Reisin E. Potential role of uric acid in metabolic syndrome, hypertension, kidney injury, and cardiovascular diseases: is it time for reappraisal? Curr Hypertens Rep. 2013;15:175-81.

49. Lyngdoh T, Vuistiner P, Marques-Vidal P, Rousson V, Gérard W, Vollenweider $P$, et al. Serum uric acid and adiposity: deciphering causality using a bidirectional Mendelian randomization approach. PLoS One. 2012;7:e39321.

50. Chaudhary K, Malhotra K, Sowers J, Aroor A. Uric acid-key ingredient in the recipe for cardiorenal metabolic syndrome. Cardiorenal Med. 2013;3:208-20.

51. FitzGerald JD, Dalbeth N, Mikuls T, Brignardello-Petersen R, Gordon G, Abeles AM, et al. 2020 American College of Rheumatology guideline for the management of gout. Arthritis Care Res. 2020;0:1-17.

52. Williams PT. Effects of diet, physical activity and performance, and body weight on incident gout in ostensibly healthy, vigorously active men. Am J Clin Nutr. 2008;87:1480-7.

53. Choi HK, Curhan G. Soft drinks, fructose consumption, and the risk of gout in men: prospective cohort study. BMJ (Clinical Research Ed). 2008; 336(7639):309-12.

54. Choi HK, Willett W, Curhan G. Fructose-rich beverages and risk of gout in women. JAMA. 2010;304:2270-8.

55. Choi JW, Ford ES, Gao X, Choi HK. Sugar-sweetened soft drinks, diet soft drinks, and serum uric acid level: the Third National Health and Nutrition Examination Survey. Arthritis Rheum. 2008;59:109-16.

56. Zykova SN, Storhaug HM, Toft I, Chadban SJ, Jenssen TG, White SL, et al. Cross-sectional analysis of nutrition and serum uric acid in two Caucasian cohorts: the AusDiab Study and the Tromsø study. Nutr J. 2015;14:49.

57. Sundy JS, Baraf HS, Yood RA, Edwards NL, Gutierrez-Urena SR, Treadwell EL, et al. Efficacy and tolerability of pegloticase for the treatment of chronic gout in patients refractory to conventional treatment: two randomized controlled trials. JAMA. 2011;306:711-20. 
58. Tausche AK, Alten R, Dalbeth N, Kopicko J, Fung M, Adler S, et al. Lesinurad monotherapy in gout patients intolerant to a xanthine oxidase inhibitor: a 6-month phase 3 clinical trial and extension study. Rheumatology (Oxford). 2017:56:2170-8.

59. Dalbeth N, Jones G, Terkeltaub R, Khanna D, Kopicko J, Bhakta N, et al. Lesinurad, a selective uric acid reabsorption inhibitor, in combination with febuxostat in patients with tophaceous gout: findings of a phase III clinical trial. Arthritis Rheumatol. 2017;69:1903-13.

60. Casey V, Dwyer JT, Berkey CS, Coleman KA, Gardner J, Valadian I. Long-term memory of body weight and past weight satisfaction: a longitudinal followup study. Am J Clin Nutr. 1991;53:1493-8.

61. Perry GS, Byers TE, Mokdad AH, Serdula MK, Williamson DF. The validity of self-reports of past body weights by U.S. adults. Epidemiology. 1995;6:61-6.

62. Sorkin JD, Muller DC, Andres R. Longitudinal change in the heights of men and women: consequential effects on body mass index. Epidemiol Rev. 1999;21(2):247-60.

63. Must A, Willett WC, Dietz WH. Remote recall of childhood height, weight, and body build by elderly subjects. Am J Epidemiol. 1993;138(1):56-64.

64. Heaney R, Ryan R. Relation between measured and recalled body height. N Engl J Med. 1988;319(12):795-6.

65. McAdams M, Maynard J, Baer A, Kottgen A, Clip S, Coresh J, et al. Reliability and sensitivity of the self-report of physician-diagnosed gout in the campaign against cancer and heart disease and the atherosclerosis risk in the community cohorts. J Rheumatol. 2011;38:135-41.

\section{Publisher's Note}

Springer Nature remains neutral with regard to jurisdictional claims in published maps and institutional affiliations.

Ready to submit your research? Choose BMC and benefit from:

- fast, convenient online submission

- thorough peer review by experienced researchers in your field

- rapid publication on acceptance

- support for research data, including large and complex data types

- gold Open Access which fosters wider collaboration and increased citations

- maximum visibility for your research: over $100 \mathrm{M}$ website views per year

At $\mathrm{BMC}$, research is always in progress.

Learn more biomedcentral.com/submissions 